\section{Dental patients' use of the Internet}

\author{
R. Ní Ríordáin ${ }^{1}$ and C. McCreary²
}

VERIFIABLE CPD PAPER

IN BRIEF
Presents information regarding the use of
the Internet by a range of dental patients
for information regarding their dental/
oral conditions.
- Details the extent of patient interest in
searching for information regarding their
dental/oral condition.
Investigates the reasons why these patients
turn to the Internet for information.
Examines the willingness of patients to
travel abroad for dental treatment.

\begin{abstract}
Aims and objectives To determine the use of the Internet by patients attending a range of dental clinics to search for information regarding dental procedures, and also to investigate their interest in online dental consultations and 'dental tourism.' Methods A questionnaire was designed and randomly distributed to 520 patients attending the restorative dentistry, dental surgery and oral medicine clinics of Cork University Dental School and Hospital. Results Of the 520 questionnaires distributed, 500 were completed leading to a response rate of $96.2 \%$. The majority of patients were familiar with using the Internet on a daily basis, with only 163 (32.6\%) patients not using the Internet in their everyday lives. One hundred and seventy-seven (34.5\%) patients either researched their presenting dental/oral condition or had a family or friend research their condition on their behalf. One hundred and eighty-five (37\%) patients would consult with a dental practitioner online regarding an oral problem and a similar number $(n=186)$ of patients surveyed would consider using the Internet to plan trips abroad for dental treatment. Conclusion Practitioner-led direction for patients regarding quality information sources online is important. With the increased interest in travelling abroad for dental treatment, guidance for patients and practitioners regarding the legal and ethical issues pertaining to dental tourism is critical.
\end{abstract}

\section{INTRODUCTION}

Between 2000 and 2008, Internet usage worldwide has almost tripled and a current population penetration of over $20 \%$ exists. ${ }^{1}$ The Internet is considered to be a significant source of health information for the general public ${ }^{2}$ and in particular for those with chronic illnesses, ${ }^{3}$ with more than 70,000 websites providing health information. ${ }^{4}$ It allows increased access to medical and dental information and can be used for patient self-education, enabling patients to confirm the information given by their practitioner and to gather additional information. ${ }^{5}$ It is also seen as a means for patients to seek support and advice both from other patients and from healthcare professionals. ${ }^{6,7}$ According to Mullen, a well-informed patient is regarded as more likely to have greater treatment

${ }^{1+}$ Clinical Fellow in Oral Medicine, ${ }^{2}$ Senior Lecturer/Consultant in Oral Medicine, Cork University Dental School and Hospital, Wilton, Cork, Ireland

*Correspondence to: Dr Richeal Ni Riordáin

Email: richeal.niriordain@ucc.ie

\section{Refereed Paper}

Accepted 24 August 2009

DOI: 10.1038/sj.bdj.2009.1137

${ }^{\circledR}$ British Dental Journal 2009; 207: 583-586 compliance and improved outcomes, ${ }^{8}$ however not all practitioners agree with this. Anderson et al. suggest that the Internet can lead to disagreements on a course of treatment resulting in tension between the practitioner and the patient.9

The Internet not only has implications for educating patients about medical and dental conditions and procedures, but with the growth in dental tourism the Internet provides a means of communication fuelling this industry. The Internet is used by dental tourism companies and travel agencies worldwide to advertise procedures to international patients. ${ }^{10}$

A number of studies have been conducted to determine the use of the Internet by patients seeking medical advice in a variety of medical specialist areas. ${ }^{11,12}$ We could find only two relevant articles in dentistry, the first explored the use of the Internet by patients attending dental hygiene clinics ${ }^{13}$ and the second looked at the perceptions of the Internet from a dentist's perspective. ${ }^{14}$ The aims of this study were to determine the use of the Internet by patients, attending a range of dental clinics, to search for information regarding dental procedures and also to investigate their interest in online dental consultations and dental tourism.

\section{MATERIALS AND METHODS}

Following an extensive review of the literature, a questionnaire was designed and piloted before being randomly distributed to 520 adult patients attending Cork University Dental School and Hospital during the period September to December 2008. Included were all clinics with an adult patient population, namely restorative, dental surgery and oral medicine clinics. A verbal explanation of the rationale behind this study was given to patients before they consented to become involved. All of the 520 patients invited to participate in this study agreed to do so. They were then given the self-administered, anonymous questionnaire to complete. The questionnaire consisted of 15 questions including patient demographics, Internet access, name of sites used, quality of information obtained, whether they would use the Internet again to source health information, whether they would be interested in consulting with a dentist online and whether they would consider using the Internet to organise foreign travel for the 
purpose of dental treatment. Local ethics committee approval was obtained.

Completed questionnaires were coded, data were recorded in a standard proforma and statistically analysed using SPSS. Frequencies were used to describe demographics and association between variables was examined using Chi-squared tests. Results were considered significant at $\mathrm{p}<0.05$.

\section{RESULTS}

Of the 520 questionnaires distributed 500 were completed, with 20 excluded due to inadequate information, leading to a response rate of $96.2 \%$. The average age of the patients involved was 44.2 years $(S D \pm 16.9)$ within a range of 18 to 85 years. A significantly greater number of females completed the questionnaire: 323 females (64.6\%), compared with 177 males (35.4\%). Educational attainment was recorded as leaving school at 15 years (18.6\%), leaving school at 18 years (36.4\%), completion of a university degree (33.8\%) and none of the above (11.2\%).

of the questionnaires included in the statistical analysis, 290 (58\%) were completed by new patients to the hospital and $210(42 \%)$ by returning patients.

$45.8 \%$ ( $n=229$ ) of patients were attending the restorative clinic, $29.8 \%(n=146)$ of patients were attending the oral medicine clinic and 25\% ( $n=125)$ of patients were attending the oral surgery clinic. Table 1 represents the categorisation of the reasons for attending the various clinics.

The majority of patients were familiar with using the Internet on a daily basis, with only $163(32.6 \%)$ patients not using the Internet in their everyday lives. One hundred and seventy-seven (34.5\%) patients either researched their presenting dental/oral condition or had a family or friend research their condition on their behalf. Figure 1 represents whether or not patients researched their dental/oral condition or procedure online based on three age categories. Table 2 represents the reasons, as derived by the authors, for seeking health information on the Internet. Google was the most frequently mentioned search engine and 18.6\% $(33 / 177)$ of these patients deemed the information to be of high quality, 73.4\% (130/177) deemed it of medium quality and $7.9 \%(14 / 177)$ of low quality. One

\section{Table 1 Categorisation of the reasons for attending the various clinics}

\begin{tabular}{l|l|l}
\hline Condition & N & $\%$ \\
\hline Burning mouth syndrome & 19 & 3.8 \\
\hline Crowns & 33 & 6.6 \\
\hline Cysts & 8 & 1.6 \\
\hline Dentures & 34 & 6.8 \\
\hline Endodontic treatment & 19 & 3.8 \\
\hline Facial pain & 12 & 2.4 \\
\hline Fillings & 88 & 17.6 \\
\hline Implants & 12 & 2.4 \\
\hline Oral lichen planus & 67 & 13.4 \\
\hline Osteotomy & 15 & 3 \\
\hline Periodontal treatment & 42 & 8.4 \\
\hline Recurrent ulceration & 14 & 2.8 \\
\hline Soft tissue lesions & 38 & 7.6 \\
\hline Surgical extraction & 62 & 12.4 \\
\hline Temporomandibular joint disorder & 20 & 4 \\
\hline Veneers & 6 & 1.2 \\
\hline Xerostomia & 11 & 2.2 \\
\hline & & \\
\hline
\end{tabular}

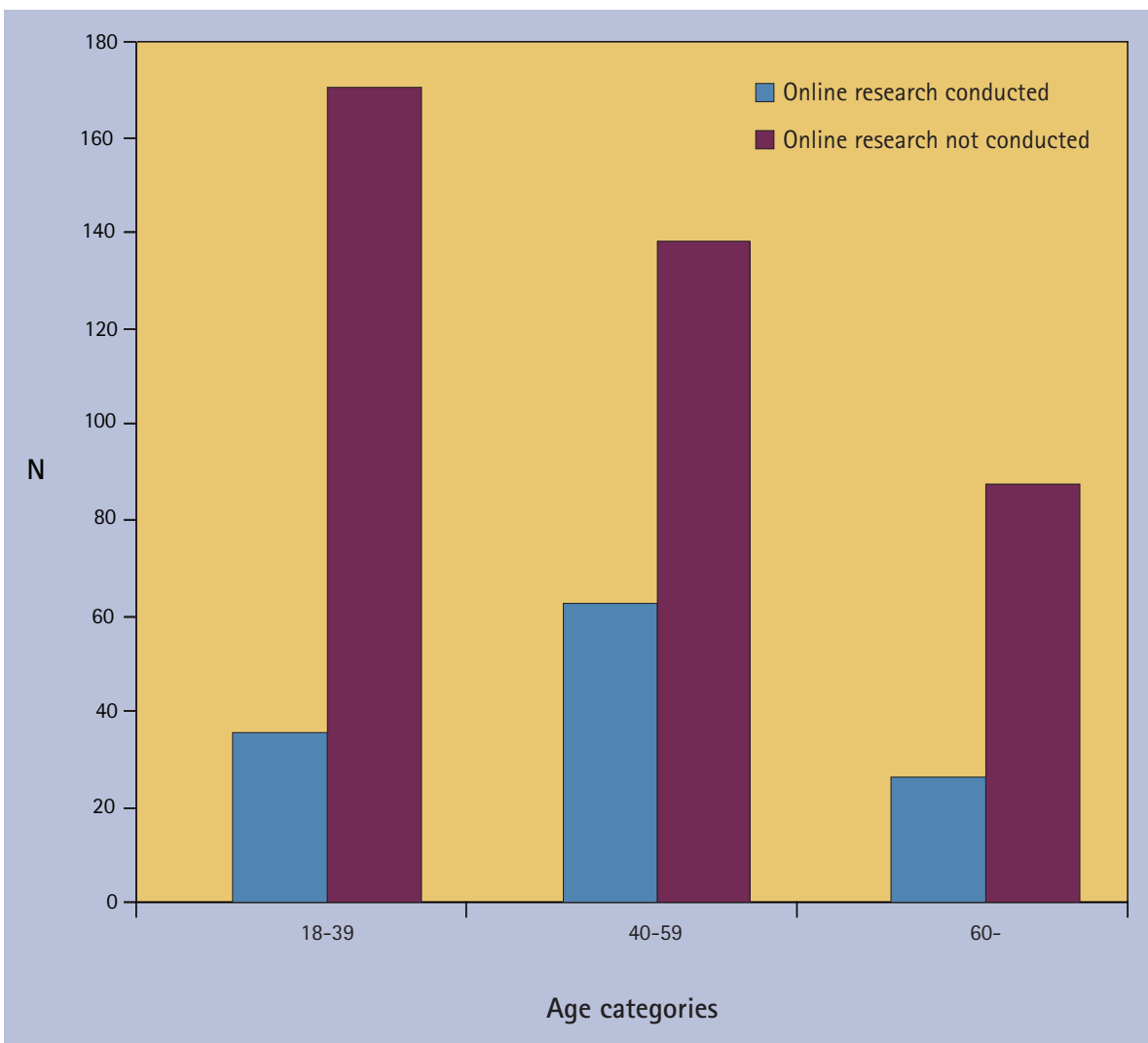

Fig. 1 Whether or not online research was conducted, by age category

hundred and thirty-three (75.1\%) of the patients who received information regarding their condition or procedure via the worldwide web would consider using the Internet again.
A statistically significant association was also found between the clinic being attended and whether the patient, family member or friend of the patient had researched their condition online 


\begin{tabular}{|c|c|c|}
\hline Reason for seeking information & $\mathrm{N}$ & $\% *$ \\
\hline Improve knowledge about the condition / procedure & 95 & 53.7 \\
\hline Reduce my anxiety & 22 & 12.4 \\
\hline Accept the condition & 26 & 14.7 \\
\hline Alternative remedies or treatment options & 28 & 15.8 \\
\hline Others with a similar condition / same procedure & 13 & 7.3 \\
\hline
\end{tabular}

$\left[\chi^{2}(1)=26.831, p<0001\right]$. Forty-nine percent of patients attending oral medicine clinics, 20\% of patients attending oral surgery clinics and $11.5 \%$ of patients attending restorative clinics reported researching their condition online.

One hundred and eighty-five (37\%) patients indicated they would consult with a dental practitioner online regarding an oral problem and a similar number ( $n=186$ ) of patients surveyed would consider using the Internet to plan trips abroad for dental treatment.

Statistically significant associations were found between home access to the Internet and whether the patients would consult with a dentist online $\left[\chi^{2}(1)=23.6\right.$, $\mathrm{p}<0.001]$ and home access to the Internet and the intention to plan a trip abroad for dental treatment (dental tourism) $\left[\chi^{2}(1)=10.06, p<0.05\right]$.

Statistically significant associations were also found between level of education and the use of the Internet for dental tourism $\left[\chi^{2}(1)=27.565, p<0.001\right]$ and level of education and whether patients would consult with a dentist online $\left[\chi^{2}(1)=22.318\right.$, $\mathrm{p}<0.001$. Sixty percent of patients with university level qualifications were willing to use the Internet to plan trips abroad for dental treatment while less than 10\% of patients with no formal educational examinations would do the same. Over $50 \%$ of patients with university level qualifications were willing to consult with a dentist online, with only $16 \%$ of patients with no formal educational examinations willing to consider consulting online with a dentist.

\section{DISCUSSION}

With the increased population penetration of the Internet in the last number of years and its availability not only in public places and in the workplace but also in the home, people have access to vast amounts of information and resources quite literally at their fingertips. This is the first study to look at the use of the Internet by a diverse group of dental patients to research their dental/oral conditions or treatments online. Although we strived to achieve a truly representative sample of dental patients in this study, a considerable proportion of the study population were in fact attending the hospital for oral medicine related conditions. This is most likely due to the questionnaires being distributed in the hospital on days with large oral medicine clinics over the period of time of the study.

$67.4 \%$ of patients surveyed were familiar with using the Internet in their daily lives and one in three patients reported using the Internet to research their dental/oral condition or procedure online. This is a higher number than previously reported in medical outpatient clinics. ${ }^{12,15}$ Of note in this study is that a similar number of patients in both the 18-39-year-old age range ( $\mathrm{n}=199$ ) and the 40-59-year-old age range $(n=194)$ researched their dental/oral condition online. Although a greater percentage of people aged between 18 and 39 years use the Internet, they tend to use the Internet more for socialising and entertainment, with older people using the Internet specifically for health information. ${ }^{16}$

Of the patients surveyed who had researched their dental/oral condition or procedure online, over 50\% reported doing so to improve their knowledge about a condition or procedure. The interpretation of medical based information is an acquired skill often lacking in patients. With the widespread availability of such information via the worldwide web, patients' search for knowledge my be fulfilled, however they may fail to recognise that important information is missing or fail to acknowledge the biased content of the information they obtain. ${ }^{17}$ Patients may also be unable to recognise non-evidence-based material and there is also a potential for misinterpretation of some of the medical information. ${ }^{18}$ Eysenbach suggests that healthcare professionals should acknowledge that patients are independently seeking information and therefore teach patients how to analyse and filter this information. ${ }^{19}$ The Journal of the American Dental Association have published guidelines for patients regarding oral health information on the Internet. ${ }^{20}$ Patients were encouraged to be cautious about information available online, to question the source, qualifications of the provider and the scientific validity of that which they read.

In a study by Chestnutt et al. the authors discovered that dental practitioners do not commonly refer patients to information on the Internet. ${ }^{14}$ Practitioners were unsure where to direct patients for high quality, reliable information and many requested a central resource to which patients could be referred. Although patient information is delivered verbally in consultation visits and in written form via patient information leaflets, patients often forget or fail to fully comprehend the information given in a dental setting. ${ }^{13}$ Perhaps, in addition, direction could be given to appropriate websites to allow patients to further research their condition or proposed treatment. It is thought that this could empower patients, allowing those who are interested and informed to assume an active role in the management of their health. ${ }^{21}$

Web-based consultation with a dentist appealed to 37\% of patients surveyed. A similar proportion of patients showed interest in online consultations with an orthopaedic consultant in an article by Gupte et $a .^{22}$ Such an online service seems unusual if not potentially dangerous in a medical or dental setting, given the importance of the sequence of history and examination before any conclusions can be drawn with regard to patient care. In some areas of medicine studies have been carried out to assess the use of the Internet to monitor a patient's progress post-discharge, with variable success. ${ }^{23,24}$ In this study patients 
were given the option to comment at the end of the questionnaire, with a number of respondents reiterating their disinterest in online consultation stating that they prefer 'the personal touch' and find the 'human contact more reassuring'.

Dental tourism is considered a growing phenomenon. In a recent article by Österle et al. the authors statistically confirmed the prominence of dental tourism in Hungary, one of the most popular destinations, with patients travelling not only from neighbouring countries but also from the UK and the USA. ${ }^{25}$ In another study it was found that approximately 45,000 Austrian and Italian patients were treated in Slovenia in the period 2000-2002. ${ }^{26}$ Companies recognise that it is possible to profit by targeting patients in regions where dental care is more expensive and selling them lower cost dental treatment. Some of the dental care these patients will receive will be of high quality while others are at risk of receiving substandard treatment. ${ }^{27}$ Dental tourism involves sporadic treatment with prolonged visits incorporating multiple procedures. Very little if any follow up care is provided and difficulties can arise if postoperative complications occur, as patients are can find it problematic to return to the clinic overseas for further care. The onus can then lie with the local practitioner to provide some form of remedial care. Turner outlines five factors influencing the increase in dental tourism: cost of treatment, delay in access to care, reports of patient satisfaction with treatment provided, economy of air travel and the Internet. ${ }^{10}$ Although the patients surveyed in this study were already availing of reduced costs for dental treatment as they were attending an educational institution, over one third of them would still consider using the Internet to plan trips abroad for dental treatment. Cost alone is not therefore the major determining factor in engaging in dental tourism, further supporting the multifactorial influences referred to by Turner. ${ }^{10}$

\section{CONCLUSION}

Chestnutt et al. have described the impact of the Internet on dentistry as positive but have also concluded that it has not fully realised its potential. ${ }^{14}$ There is no doubt that there is much benefit to be elicited for patients from the use of the Internet in allowing them to become empowered in relation to their dental health. However, the potential for misinformation or misinterpretation of information remains an issue. Patient demand for information is evident and so practitioner-led guidance for patients regarding quality information sources online, due to the increased availability of the Internet in home around the world, is important. With the increased interest in travelling abroad for dental treatment, guidance for patients and practitioners regarding the legal and ethical issues pertaining to dental tourism is critical.

1. Internet World Stats. Internet usage statistics: the Internet big picture. World Internet users and population stats. www.internetworldstats.com/stats.htm (accessed 24 November 2009).

2. McMullan M. Patients using the Internet to obtain health information: how this affects the patienthealth professional relationship. Patient Educ Couns 2006: 63: 24-28.

3. Wagner T H, Baker LC, Bundorf M K, Singer S. Use of the Internet for heath information by the chronically ill. Prev Chronic Dis 2004; 1: A13.

4. Grandinetti D A. Doctors and the web: help your patients surf the net safely. Med Econ 2000; 77(5): 186-188, 194-196, 201.

5. Nicholas D, Huntington P, Gunter B, Russell C, Withey R. The British and their use of the web for health information and advice: a survey. Aslib Proc 2003; 55: 261-276.

6. Cline R J W, Haynes K M. Consumer health information seeking on the Internet: the state of the art. Health Educ Res 2001; 16: 671-692.

7. Ziebland S, Chapple A, Dumelow C, Evans J, Prinjha $S$, Rozmovits L. How the internet affects patients' experience of cancer: a qualitative study. BMJ 2004; 328: 564

8. Mullen P D. Compliance becomes concordance. BMJ 1997; 314: 691
9. Anderson J G, Rainey M R, Eysenbach G. The impact of CyberHealthcare on the physician-patient relationship. J Med Syst 2003; 27: 67-84.

10. Turner L. Cross-border dental care: 'dental tourism' and patient mobility. Br Dent J 2008; 204: 553-554.

11. Roshandel D, Rezailashkajani M, Ansari S, Zali M R. Internet use by a referral gastroenterology clinic population and their medical information preferences. Int J Med Inform 2005; 74: 447-459.

12. Tassone P, Georgalas C, Patel N N, Appleby E, Kotecha B. Do otolaryngology out-patients use the internet prior to attending their appointment? J Laryngol Otol 2004; 118: 34-38.

13. Harris C E, Chestnutt I G. The use of the Internet to access oral health-related information by patients attending dental hygiene clinics. Int J Dent Hygiene 2005; $3:$ 70-73

14. Chestnutt I G, Reynolds K. Perceptions of how the Internet has impacted on dentistry. Br Dent J 2006; 200: 161-165

15. Gordon M M, Capell H A, Madhok R. The use of the Internet as a resource for health information among patients attending a rheumatology clinic. Rheumatology 2002; 41: 1402-1405.

16. Jones S, Fox S. Generations online in 2009. Pew Internet \&t American Life Project, January 282009. http://pewinternet.org/Reports/2009/GenerationsOnline-in-2009.aspx (accessed 24 November 2009).

17. Sacchetti P, Zvara P, Plante M K. The Internet and patient education - resources and reliability: focus on a selected urologic topic. Urology 1999; 53: $1117-1120$.

18. Ayonrinde 0 . Patients in cyberspace: information or confusion? Postgrad Med J 1998; 74: 449-450.

19. Eysenbach $\mathrm{G}$. The impact of the Internet on cancer outcomes. CA Cancer J Clin 2003; 53: 356-371.

20. ADA Division of Communications; ADA Council on Scientific Affairs. For the dental patient... Surfing for substance: evaluating oral health information on the Internet. J Am Dent Assoc 2006; 137: 692.

21. Neelapala P, Duvvi S K, Kumar G, Kumar B N. Do gynaecology outpatients use the Internet to seek health information? A questionnaire survey. J Eval Clin Pract 2008; 14: 300-304.

22. Gupte C M, Hassan A N A, McDermott I D, Thomas R D. The Internet - friend or foe? A questionnaire study of orthopaedic out-patients. Ann R Coll Surg Eng/ 2002; 84: 187-192.

23. Aucar J A, Doarn C R, Sargsyan A, Samuelson D A, Odonnell M J, DeBakey M E. Use of the Internet for long-term clinical follow-up. Telemed J 1998; 4: 371-374.

24. Peckham B. Internet access for ESRD patients gives new meaning to "sleepless in Seattle". Northwest kidney centers wire all stations at newest unit. Nephrol News Issues 1999; 13(1): 18-19.

25. Österle A, Balázs P, Delgado J. Travelling for teeth: characteristics and perspectives of dental care tourism in Hungary. Br Dent J 2009; 206: 425-428.

26. Albrecht T, Pribakovix Brinovec R, Stalc J. Crossborder care in the south: Slovenia, Austria and Italy. In Rosenmoller M, McKee M, Baeten R (eds) Patient mobility in the European Union - learning from experience. 1st ed. pp 9-22. Copenhagen: European Observatory of Health Systems and Policies, 2006.

27. Asai $R$, Jones K. Ethical moment: am I obligated to treat a patient whose need for emergency care stems from dental tourism? J Am Dent Assoc 2007; 138: 1018-1019. 